\title{
Ring-Opening Polymerization of 3,3,3-Trifluoro-1,2-epoxypropane. Studies on Monomer Reactivity and Polymer Structure
}

\author{
Junko Umezawa, ${ }^{\dagger}$ Tokio Hagiwara, ${ }^{*}$ Hiroshi Hamana, ${ }^{*}$ Tadashi Narita, ${ }^{*}$ \\ Keizo FurUhaShI,** and Hiroyuki NoHIRA \\ Department of Applied Chemistry, Faculty of Enginnering, Saitama University, \\ Shimo-ohkubo, Urawa, Saitama 338, Japan \\ * Department of Environmental Engineering, Saitama Institute of Technology, \\ Fusaiji, Okabe, Saitama 369-02, Japan \\ ** Parmaceuticals \& Biotechnology Laboratory, JAPAN ENERGY CORPORATION, \\ Niizo-Minami, Toda, Saitama 335, Japan
}

(Received November 17, 1993)

\begin{abstract}
The polymerization reaction of 3,3,3-trifluoro-1,2-epoxypropane (TFEP) with $\mathrm{Et}_{2} \mathrm{Zn}-\mathrm{H}_{2} \mathrm{O}$ or potassium hydroxide was investigated. The ring-cleavage reaction of TFEP occurs only at the $\beta\left(\mathrm{CH}_{2}-\mathrm{O}\right)$-position to give regioregular, head-to-tail poly(TFEP). The ${ }^{13} \mathrm{C}$ NMR and ${ }^{19} \mathrm{~F}$ NMR spectra of the polymer give information on the dyad tacticity of the polymer main chain. It is suggested that the organozinc compound is a stereospecific catalyst and potassium hydroxide is a non-stereospecific one for the polymerization of TFEP.
\end{abstract}

KEY WORDS Ring-Opening Polymerization / 3,3,3-Trifluoro-1,2-epoxypropane / Organozinc / Potassium Hydroxide / Tacticity / ${ }^{19} \mathrm{~F}$ NMR /

Numerous studies have been carried out on the ring-opening reaction and polymerization of 1,2-epoxypropane (EP). In the basecatalyzed reaction of EP with alcohols, the cleavage of the oxirane ring prefers to occur at the $\beta\left(\mathrm{CH}_{2}-\mathrm{O}\right)$-position with a selectivity of $95 \% .^{1}$ During polymerizations of EP with usual anionic or anionic-coordination initiators, ring-opening of the oxirane ring also occurs predominantly at the $\beta$-position, resulting in the formation of regioregular, head-to-tail poly(EP)s. ${ }^{2-4}$ NMR spectra of poly(EP)s prepared using several types of initiators have been analyzed in order to get information on the tacticity of the polymers. The methylene and methine carbons in the ${ }^{13} \mathrm{C}$ NMR spectrum of poly(EP) clearly exhibit the dyad and triad, respectively. ${ }^{1,5-13}$ Stereoregular (isotactic) polymers are obtained using
$\mathrm{Et}_{2} \mathrm{Zn} / \mathrm{alcohol}$ or $\mathrm{Et}_{2} \mathrm{Zn}-\mathrm{H}_{2} \mathrm{O}$ as an initiator, ${ }^{1,8,9}$ while stereoirregular (atactic) polymers are given by potassium hydroxide- or tert-butoxide-mediated polymerization. ${ }^{1,8}$

We previously reported that 3,3,3-trifluoro1,2-epoxypropane (TFEP) polymerized with $\mathrm{Et}_{2} \mathrm{Zn}$ /alcohol or alkali metal alkoxides. ${ }^{14} \mathrm{It}$ is known that TFEP also polymerizes with ferric chloride, aluminum chloride, boron trifluoride or potassium hydroxide. In this connection, several groups propose mechanisms for the polymerizations and terminations initiated by some initiators. ${ }^{15-18}$ However, the tacticity of these polymers has not been studied.

This paper describes the regioregularity and stereoregularity of poly(TFEP)s obtained using several initiators.

\footnotetext{
† To whom correspondence should be addressed.
} 


\section{EXPERIMENTAL}

All experiments related to the polymerization reaction were carried out under a nitrogen atmosphere in order to exclude oxygen and moisture.

\section{Reagents}

$(S)-3,3,3$-Trifluoro-1,2-epoxypropane (TFEP: $75 \%$ e.e.) was prepared from 3,3,3trifluoropropene by fermentation with $\mathrm{No}$ cardia corallina ${ }^{19}$ and purified by distillation after refluxing over calcium hydride. Optically pure $(S)$-TFEP $(100 \%$ e.e.) was synthesized from trifluorolactic acid according to the outlined procedure by Seebach et al. ${ }^{20}$ and purified in a similar way.

Toluene was successively washed with concd. sulfuric acid, water, diluted sodium hydroxide, and water, and then dried over calcium chloride. Toluene was refluxed over sodium and distilled. 1,2-Dimethoxyethane (DME) was distilled after refluxing over calcium hydride. 1,4-Dioxane was distilled after refluxing over sodium. Distilled water was degassed with helium. Diethylzinc in hexane (Kanto Chemical Co., Inc.) was used without further purification. Potassium hydroxide (purity $86 \%$ ) was used without further purification.

\section{Preparation of Initiators}

$\left[\mathrm{Zn}(\mathrm{OMe})_{2}(\mathrm{EtZnOMe})_{6}\right]$ and $[\mathrm{EtZnOMe}]_{4}$ were prepared as previously reported, $, 9,21,22$ and used as a toluene solution.

$\mathrm{Et}_{2} \mathrm{Zn}-\mathrm{H}_{2} \mathrm{O}(1: 0.8)$ and $\left[\mathrm{Zn}(\mathrm{OMe})_{2}\right]_{n}$ were prepared in a glass tube under nitrogen just before use. $\mathrm{Et}_{2} \mathrm{Zn}-\mathrm{H}_{2} \mathrm{O}(1: 0.8)$ was prepared as follows: A tube connected to a vacuum line was filled with dry nitrogen. A solution of diethylzinc $(0.617 \mathrm{~g}, 0.5 \mathrm{mmol})$ in hexane $(0.5 \mathrm{ml})$ was charged into the tube, and a solution of water $(0.0072 \mathrm{~g}, 0.4 \mathrm{mmol})$ in dioxane $(0.2 \mathrm{ml})$ was added by syringe. Stirring was continued at room temperature for $0.5 \mathrm{~h}$ and then at $60^{\circ} \mathrm{C}$ for $0.5 \mathrm{~h}$. The resulting yellow slurry was dried under vacuum in order to remove unreacted diethylzinc, hexane, and dioxane. The residue thus obtained was used as a catalyst. $\left[\mathrm{Zn}(\mathrm{OMe})_{2}\right]_{n}$ was similarly prepared by using a solution of diethylzinc $(0.617 \mathrm{~g}, 0.5 \mathrm{mmol})$ in hexane $(0.5 \mathrm{ml})$ and methanol (0.04 ml, $0.99 \mathrm{mmol})$.

Potassium hydroxide was ground into powdèr, charged in a tube and dried under reduced pressure.

\section{Polymerization and Isolation of Polymer}

$9 \mathrm{ml}$ of solvent, $23 \mathrm{mmol}(2 \mathrm{ml})$ of TFEP, and $0.5 \mathrm{mmol}$ of an initiator species (an organozinc compound) were placed in a glass tube under a purified nitrogen atmosphere, and the tube was sealed. When potassium hydroxide was used as an initiator, $8 \mathrm{ml}$ of solvent, $12 \mathrm{mmol}$ $(1 \mathrm{ml})$ of TFEP, and $0.13 \mathrm{~g}(1.9 \mathrm{mmol})$ of potassium hydroxide were placed, and the tube was similarly sealed. Polymerization was carried out at constant temperature with stirring for a definite time. The reaction mixture was poured into a large amount of methanol containing a small quantity of concd. hydrochloric acid. The polymer precipitated was separated by filtration, washed with methanol and dried in vacuo at $60^{\circ} \mathrm{C}$. When the polymer could not be precipitated, the reaction mixture was dissolved in diethyl ether, washed successively with diluted hydrochloric acid and water to remove the initiator residue. After removal of the solvent, the resulting solid mass was dried in vacuo at $60^{\circ} \mathrm{C}$.

\section{Measurements}

GPC was measured at $55^{\circ} \mathrm{C}$ with double Shodex KF-80M columns using THF as the eluent (flow rate, $0.5 \mathrm{ml} \mathrm{min} \mathrm{m}^{-1}$ ). Molecular weight was calibrated using polystyrene standard samples.

${ }^{13} \mathrm{C}$ and ${ }^{19} \mathrm{~F}$ NMR spectra were recorded on a JEOL JNM-GSX 270 FT-NMR spectrometer at $50^{\circ} \mathrm{C}$ using deuterated acetone as solvent. ${ }^{13} \mathrm{C}$ NMR spectra were measured under the proton-decoupled conditions. 
Chemical shifts are given in ppm with plus value for downfield shift ( $\delta$-scale) from tetramethylsilane (TMS) for ${ }^{13} \mathrm{C} \mathrm{NMR}$ as well as trifluoroacetic acid for ${ }^{19} \mathrm{~F}$ NMR.

\section{RESULTS AND DISCUSSION}

\section{Polymerization Reactivity of TFEP}

Table I shows the results for the polymerization of 3,3,3-trifluoro-1,2-epoxypropane (TFEP) initiated with $\mathrm{Et}_{2} \mathrm{Zn}-\mathrm{H}_{2} \mathrm{O}(1: 0.8)$ or potassium hydroxide. The polymerization was carried out at room temperature or at $80^{\circ} \mathrm{C}$ for $24 \mathrm{~h}$. Polymerization reactivity was estimated on the basis of the isolated yield of the polymer.

TFEP could be polymerized with $\mathrm{Et}_{2} \mathrm{Zn}-$ $\mathrm{H}_{2} \mathrm{O}$ as well as the $\mathrm{Et}_{2} \mathrm{Zn} /$ alcohol system. ${ }^{14}$ $\mathrm{Et}_{2} \mathrm{Zn}-\mathrm{H}_{2} \mathrm{O}$ initiator gave a white hard polymer with high molecular weight (GPC peak, $M_{\mathrm{GPC}}>10^{6}$ ) similar to the polymers ${ }^{14}$ obtained with other organozinc initiators. However, it should be emphasized that the polymeization reaction with $\mathrm{Et}_{2} \mathrm{Zn}-\mathrm{H}_{2} \mathrm{O}$ readily proceeds at room temperature. The activity of $\mathrm{Et}_{2} \mathrm{Zn}-\mathrm{H}_{2} \mathrm{O}$ is fairly higher than other organozinc initiators, with which the

Table I. Polymerization of 3,3,3-trifluoro-1,2epoxypropane (TFEP) with $\mathrm{Et}_{2} \mathrm{Zn}-\mathrm{H}_{2} \mathrm{O}$ or $\mathrm{KOH}$ initiator under various conditions ${ }^{\mathrm{a}}$

\begin{tabular}{|c|c|c|c|c|c|}
\hline \multirow{2}{*}{ Initiator } & \multirow{2}{*}{ Solvent } & Temp & Time & Yield & \multirow{2}{*}{$\begin{array}{c}\text { Polymer } \\
\text { form }\end{array}$} \\
\hline & & ${ }^{\circ} \mathrm{C}$ & $\mathrm{h}$ & $\%$ & \\
\hline \multirow{3}{*}{$\begin{array}{c}\mathrm{Et}_{2} \mathrm{Zn}-\mathrm{H}_{2} \mathrm{O} \\
(1: 0.8)\end{array}$} & $-^{c}$ & $\mathrm{rt}$ & 24 & 100 & S \\
\hline & Toluene & $\mathrm{rt}$ & 24 & 100 & $S$ \\
\hline & $\mathrm{DME}^{\mathrm{d}}$ & $\mathrm{rt}$ & 24 & 7 & $S$ \\
\hline \multirow[t]{6}{*}{$\mathrm{KOH}$} & $-^{c}$ & $\mathrm{rt}$ & 24 & 96 & $S$ \\
\hline & $-^{c}$ & 80 & 24 & 92 & $\mathrm{O}$ \\
\hline & Toluene & $\mathrm{rt}$ & 24 & 0 & - \\
\hline & Toluene & 80 & 24 & 93 & $\mathrm{O}$ \\
\hline & DME & $\mathrm{rt}$ & 24 & 98 & $\mathrm{~S}$ \\
\hline & DME & 80 & 24 & 71 & $\mathrm{O}$ \\
\hline
\end{tabular}

a Polymerization conditions: $\left[\mathrm{Et}_{2} \mathrm{Zn}-\mathrm{H}_{2} \mathrm{O}\right] /[\mathrm{TFEP}]=$ $2 / 100 ; \quad[\mathrm{KOH}] /[\mathrm{TFEP}]=17 / 100 ; \quad[\mathrm{TFEP}]=2.6$ $\mathrm{mmol} \mathrm{ml^{-1 }}$.

b S, solid; O, oil.

c Bulk polymerization.

d 1,2-Dimethoxyethane. polymerizations require to be heated at $80^{\circ} \mathrm{C}$. The yield of polymer was affected by the solvent used. When polymerization was carried out in toluene or bulk, polymerization proceeded as a heterogeneous system with the precipitation of white poly(TFEP). Under such conditions, $\mathrm{Et}_{2} \mathrm{Zn}-\mathrm{H}_{2} \mathrm{O}$ gave poly(TFEP) in almost quantitative yield. On the other hand, in 1,2-dimethoxyethane (DME) the polymerization proceeded homogeneously without precipitation, resulting in lower yield compared to that in toluene or bulk. Poly(TFEP) produced with $\mathrm{Et}_{2} \mathrm{Zn}-\mathrm{H}_{2} \mathrm{O}$ swelled in acetone, tetrahydrofuran (THF), and DME. There was no good solvent to dissolve this polymer. This suggests that the molecular weight of poly (TFEP), obtained with $\mathrm{Et}_{2} \mathrm{Zn}-\mathrm{H}_{2} \mathrm{O}$, is higher than that of the polymers obtained with other organozinc initiators, which are soluble in ethyl acetate, THF, and DME.

Bulk polymerization of TFEP with potassium hydroxide at $80^{\circ} \mathrm{C}$ gave only oily product with low molecular weight $\left(M_{\mathrm{GPC}} \approx 10^{3}\right)$. This result is in accordance with previous reports. ${ }^{17,18}$ However, the same reaction at room temperature gave a white powdery polymer with a little higher molecular weight $\left(M_{\mathrm{GPC}} \approx\right.$ $10^{4}$ ) in good yield. The ratio of the initiator to the monomer gave no effect on the molecular weight of the polymer, since only a part of potassium hydroxide worked as an initiator during polymeization because of low solubility in the solvent. For the solution polymerization of TFEP with potassium hydroxide, the polymer forms and yields were considerably affected by polymerization temperature. Polymerization took place in DME at both $\mathrm{rt}$ and $80^{\circ} \mathrm{C}$, to give powdery and oily polymers, respectively in moderate to excellent yield. However, no polymer was obtained at $\mathrm{rt}$ in toluene, while only oily polymer was produced at $80^{\circ} \mathrm{C}$ in good yield. These powdery and oily poly(TFEP)s showed higher solubility than those produced with organozinc initiators. Poly(TFEP) obtained with potassium hydroxide was soluble in ethyl acetate, acetone, 
methanol, acetonitrile, THF, DME, diethyl ether, dioxane, DMF, and pyridine, and insoluble in chloroform, benzene, toluene, and hexane. Different solubilities between poly (TFEP)s obtained with organozinc initiators and potassium hydroxide may be attributable to differences of molecular weights and/or tacticities. The GPC chromatograms showed that poly(TFEP) with potassium hydroxide had relatively narrow molecular weight distribution, while organozinc initiators produced poly(TFEP) with very broad molecular weight distribution.

\section{Regioregularity of Poly (TFEP)}

The regioregularity of poly(TFEP)s produced by various initiators can be discussed referring to the ring-cleavage reaction of TFEP with alcohols under basic and acidic conditions as previous study for poly(EP). ${ }^{1,23,24}$ Ringopening reaction of TFEP with ethanol in the presence of concd. sulfuric acid or potassium hydroxide gave only 1-ethoxy-3,3,3-trifluoro2-propanol, as a $\beta\left(\mathrm{CH}_{2}-\mathrm{O}\right)$-position cleaved product, as reported by McBee et al. ${ }^{25}$ Further, for TFEP, no $\alpha(\mathrm{CH}-\mathrm{O})$-position cleaved product but only the $\beta$-cleaved product was obtained even by Friedel-Crafts type reaction, ${ }^{26}$ which gave predominantly the $\alpha$ cleaved product for EP. ${ }^{27}$ These results suggest that ring-opening reaction of TFEP by nucleophiles takes place exclusively at the $\beta$-position under both acidic and basic conditions, probably because of the strong inductive effect of the trifluoromethyl group in TFEP. Therefore it is reasonably considered that ringopening occurs only at the $\beta$-position to give regioregular, head-to-tail poly(TFEP)s in the polymerizations of TFEP, with potassium hydroxide as an usual anionic initiator, and with $\mathrm{Et}_{2} \mathrm{Zn}-\mathrm{H}_{2} \mathrm{O}$ as an anionic-coordination initiator.

\section{Stereoregularity of Poly(TFEP)}

TFEP produced by microbial oxidation is an optically active form with $75 \%$ enantiomeric excess (e.e.). Moreover, poly(TFEP) did not contain head-to-head nor tail-to-tail linkage along the main chain. The splitting of peaks in the NMR spectra of poly(TFEP) would be considered to originate from stereochemically different sequences in the polymer chain.

Valuable information on the tacticity of poly(EP) has been given by ${ }^{13} \mathrm{C}$ NMR. In the ${ }^{13} \mathrm{C}$ NMR of poly(EP), methylene and methine carbons clearly exhibit the dyad and triad, respectively. In a similar manner, the stereoregularity of poly(TFEP) was studied by ${ }^{13} \mathrm{C}$ NMR. The ${ }^{13} \mathrm{C}$ NMR spectra of poly(TFEP)s, obtained with $\mathrm{Et}_{2} \mathrm{Zn}-\mathrm{H}_{2} \mathrm{O}$ and potassium hydroxide, in deuterated acetone, are illustrated in Figures 1 and 2. Resonances at $\delta$ $71-72,78-80$, and $119-132 \mathrm{ppm}$ are assigned to the $\mathrm{CH}_{2}$-carbon, $\mathrm{CH}$-carbon, and $\mathrm{CF}_{3}$-carbon, respectively. In the methylene and methine regions, splitting peaks changed their intensities by the polymerization initiator. With respect to the tacticity, assignments of splitting peaks in methylene and methine regions were not completely established in a previous paper. ${ }^{14}$ In order to establish the assignment of each peak in the ${ }^{13} \mathrm{C}$ NMR spectrum, we synthesized poly(TFEP) using optically pure TFEP synthesized from trifluorolactic acid, ${ }^{25}$ instead of microbially produced TFEP as a monomer. This polymer should be completely isotactic poly(TFEP) since ring-

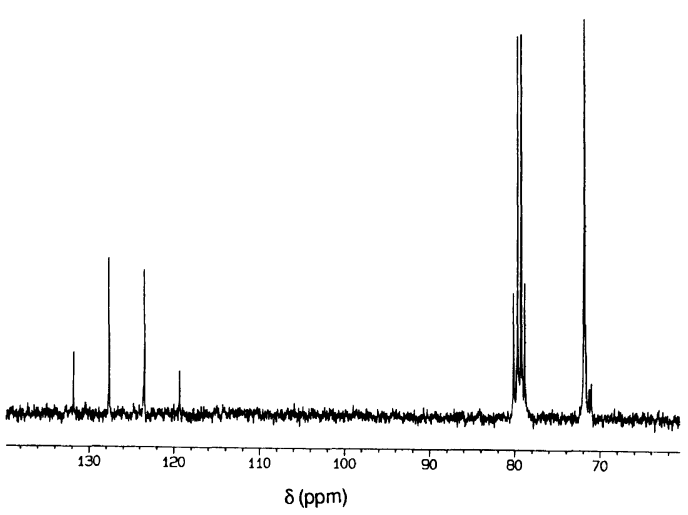

Figure 1. Proton noise-decoupled ${ }^{13} \mathrm{C}$ NMR spectrum of poly(TFEP) prepared from 75\% e.e.-TFEP with $\mathrm{Et}_{2} \mathrm{Zn}-\mathrm{H}_{2} \mathrm{O}$ initiator at $\mathrm{rt}$. 


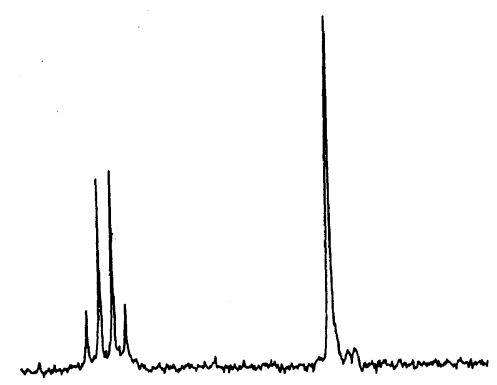

(A)
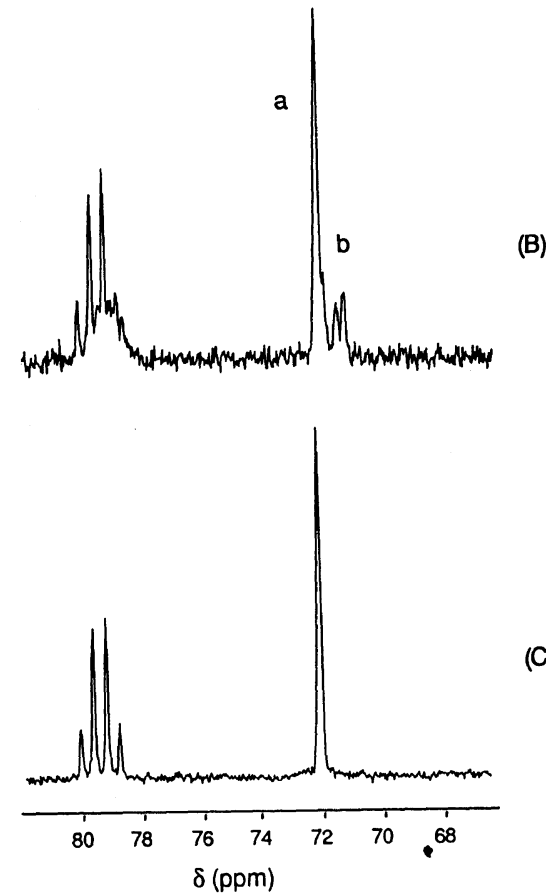

Figure 2. Proton noise-decoupled ${ }^{13} \mathrm{C}$ NMR spectra in methylene and methine carbon regions of poly(TFEP)s. (A) prepared from $75 \%$ e.e.-TFEP with $\mathrm{Et}_{2} \mathrm{Zn}-\mathrm{H}_{2} \mathrm{O}$ initiator at $\mathrm{rt}$; (B) prepared from $75 \%$ e.e.-TFEP with $\mathrm{KOH}$ initiator at $\mathrm{rt}$; (C) prepared from $100 \%$ e.e.-TFEP with $\mathrm{KOH}$ initiator at rt. Two peaks at $71.99 \mathrm{ppm}$ (a) and $71.18 \mathrm{ppm}$ (b) in the methylene carbon region can be assigned to isotactic and syndiotactic dyads, respectively.

opening polymerization is regioselective. The ${ }^{13} \mathrm{C}$ NMR spectrum of isotactic poly(TFEP) showed only one singlet peak of the methylene carbon at $71.99 \mathrm{ppm}$ as well as qualtet peaks of the methine carbon in $78.5-80.5 \mathrm{ppm}$ without any shoulder peak (Figure 2(c)). Two peaks at 71.99 and $71.18 \mathrm{ppm}$ in the methylene carbon region of poly(TFEP)s prepared from
Table II. ${ }^{13} \mathrm{C}$ NMR analysis of tacticity of poly(TFEP) with various initiators ${ }^{\mathrm{a}}$

\begin{tabular}{clcc} 
& & \multicolumn{2}{c}{ Dyads $^{\mathrm{b}}$} \\
\cline { 3 - 4 } Entry & \multicolumn{1}{c}{ Initiator } & iso (a) & syndio (b) \\
& & 79 & 21 \\
1 & $\mathrm{KOH}$ & 91 & 9 \\
2 & $\mathrm{Et}_{2} \mathrm{Zn}-\mathrm{H}_{2} \mathrm{O}(1: 0.8)$ & 91 & 9 \\
3 & {$\left[\mathrm{Zn}(\mathrm{OMe})_{2}(\mathrm{EtZnOMe})_{6}\right]$} & 91 & 9 \\
4 & {$[\mathrm{EtZnOMe}]_{4}$} & 90 & 10 \\
5 & {$\left[\mathrm{Zn}(\mathrm{OMe})_{2}\right]_{n}$} & & \\
\hline
\end{tabular}

a Monomer ( $75 \%$ e.e.) produced by microbial reaction was used.

b Area ratio of the methylene regions. Refer to Figure 2.

$75 \%$ e.e.-TFEP can be readily assigned to the isotactic and syndiotactic dyads ( $a$ and $b$ ), respectively, referring to the results from isotactic poly(TFEP). The area ratios $(a / b)$ of the two peaks are listed in Table II. The ratio $\mathrm{a} / \mathrm{b}=$ 79/21 for poly(TFEP), obtained with potassium hydroxide, is in good agreement with the value of $78 / 22$ for the ratio of iso/syndio dyad tacticity calculated on the assumption that stereoreguration of the monomer $((S)$-TFEP/ $(R)$-TFEP $=87.5 / 12.5)$ follows Bernoullian trial. The peak assigned to the syndiotactic dyad splits further due to higher ordered microstructures such as observed in the spectrum of poly(EP). ${ }^{8}$ Poly(TFEP) obtained with organozinc compounds showed higher isotacticity $(a / b=91 / 9)$ than that with potassium hydroxide. This indicates that TFEP monomer is stereospecifically incorporated into the polymer chain in the polymerization initiated by organozinc compounds. Polymerization of $75 \%$ e.e.-EP using $\left[\mathrm{Zn}(\mathrm{OMe})_{2}(\mathrm{EtZnOMe})_{6}\right]$ showed little substituent effect $\left(\mathrm{CH}_{3}\right.$ vs. $\left.\mathrm{CF}_{3}\right)$ on dyad tacticity observed in the ${ }^{13} \mathrm{C}$ NMR spectrum.

The determination of triad tacticity could not be completed since signals around $79 \mathrm{ppm}$ for the methine region of poly(TFEP) were very complicated due to spin-spin coupling with fluorine atoms, though assignments of the triad tacticity of poly(EP) were established based on splitting of the methine carbon. Each 


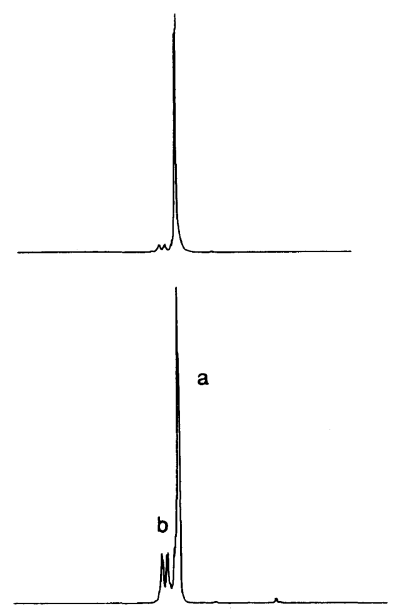

(A)

(B)

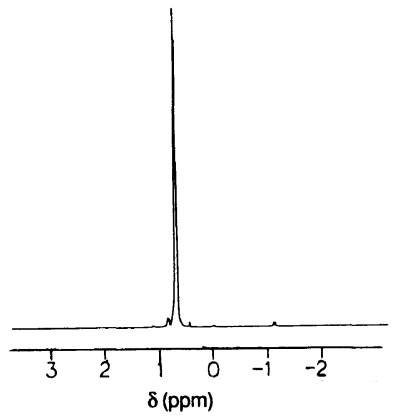

(C)

Figure 3. ${ }^{19} \mathrm{~F}$ NMR spectra of poly(TFEP)s. (A) prepared from $75 \%$ e.e.-TFEP with $\mathrm{Et}_{2} \mathrm{Zn}-\mathrm{H}_{2} \mathrm{O}$ initiator at rt; (B) prepared from $75 \%$ e.e.-TFEP with $\mathrm{KOH}$ initiator at $\mathrm{rt}$; (C) prepared from $100 \%$ e.e.-TFEP with $\mathrm{KOH}$ initiator at rt. Two peaks of $0.6-0.8 \mathrm{ppm}(a)$ and $0.8-1.0$ ppm $(b)$ in the trifluoromethyl fluoride regions can be assigned to isotactic and syndiotactic dyads, respectively.

fluorine-coupled methine peak is accompanied by small shoulder peaks which intimate the triad tacticity, but not enough to be resolved to measure the ratio of iso/hetero/syndio.

However, fluorine atoms should also provide the information of polymer structure on poly(TFEP), which could not be obtained in poly(EP). ${ }^{19} \mathrm{~F}$ NMR spectra of poly(TFEP)s were also measured to clarify the microstructures of poly(TFEP)s. Fortunately, splitting signals due to the microstructure of the polymers were observed in the ${ }^{19} \mathrm{~F}$ NMR spectra. The ${ }^{19} \mathrm{~F}$ NMR spectra of poly (TFEP)s, obtained with $\mathrm{Et}_{2} \mathrm{Zn}-\mathrm{H}_{2} \mathrm{O}$ and
Table III. ${ }^{19} \mathrm{~F}$ NMR analysis of tacticity of poly(TFEP) with various initiators ${ }^{\mathrm{a}}$

\begin{tabular}{clcc}
\hline \multirow{2}{*}{ Entry } & \multicolumn{2}{c}{ Initiator } & \multicolumn{2}{c}{ Dyads $^{\mathbf{b}}$} \\
\cline { 3 - 4 } & & iso $(a)$ & syndio $(b)$ \\
\hline 1 & $\mathrm{KOH}$ & 75 & 25 \\
2 & $\mathrm{Et}_{2} \mathrm{Zn}-\mathrm{H}_{2} \mathrm{O}(1: 0.8)$ & 90 & 10 \\
3 & {$\left[\mathrm{Zn}(\mathrm{OMe})_{2}(\mathrm{EtZnOMe})_{6}\right]$} & 91 & 9 \\
4 & {$[\mathrm{EtZnOMe}]_{4}$} & 92 & 8 \\
5 & {$\left[\mathrm{Zn}(\mathrm{OMe})_{2}\right]_{n}$} & 89 & 11 \\
\hline
\end{tabular}

${ }^{a}$ Monomer ( $75 \%$ e.e.) produced by microbial reaction was used.

b Area ratio of the trifluoromethyl regions. Refer to Figure 3.

potassium hydroxide, are illustrated in Figure 3. Resonance at $\delta 0.6-1.0 \mathrm{ppm}$ can be assigned to $\mathrm{CF}_{3}$ fluorine. Splitting of the signal is similar to that of the methylene region in the ${ }^{13} \mathrm{C} \mathrm{NMR}$ spectra. The intensity ratios of the two peaks at $0.6-0.8$ and $0.8-1.0 \mathrm{ppm}$ in the ${ }^{19} \mathrm{~F}$ NMR spectra are in good agreement with the ratios of the iso/syndio dyad tacticity estimated on the basis of the ${ }^{13} \mathrm{C}$ NMR spectra (Table III). Moreover, further splitting of each peak was observed probably due to a higher ordered microstructure and the spin-spin coupling with proton. The peak at $0.8-1.0 \mathrm{ppm}$ in the ${ }^{19} \mathrm{~F}$ NMR spectrum, intimated the syndiotactic dyad, disappeared when poly(TFEP) was prepared from the optically pure monomer (Figure 3(c)) similarly to the case of ${ }^{13} \mathrm{C}$ NMR.

In the spectrum of oily poly(TFEP) obtained with potassium hydroxide at $80^{\circ} \mathrm{C}$, additional signals were observed in the ${ }^{13} \mathrm{C}$ and ${ }^{19} \mathrm{~F}$ NMR spectra probably due to the terminal units. These signals were not observed for other polymers with higher molecular weight, and the intensity of these peaks increased with decreasing molecular weight.

On the basis of ${ }^{13} \mathrm{C}$ NMR and ${ }^{19} \mathrm{~F}$ NMR spectra, the dyad tacticity of poly(TFEP) could be estimated. The dyad tacticity of the polymer chain was affected by the polymerization initiator used. When potassium hydroxide was used as initiator, TFEP monomer was 
non-stereospecifically incorporated into the polymer chain during anionic polymerization, and the ratio of iso/syndio was in agreement with the value calculated by Bernoullian trial on the basis of the stereoreguration of the monomer. On the other hand, when organozinc compounds which are good stereospecific initiators for polymerization of EP, were used, the anionic-coordination polymerization of TFEP proceeded stereospecifically, and the isotacticity of the polymer was higher than that obtained with potassium hydroxide.

\section{REFERENCES}

1. L. C. Case and N. H. Rent, Polym. Lett., 2, 417 (1964).

2. H. Tani, N. Oguni, and S. Watanabe, Polym. Lett., 6, 577 (1968).

3. E. J. Vandenberg, J. Polym. Sci., A-1, 7, 525 (1969).

4. C. C. Price and R. Spector, J. Am. Chem. Soc., 87, 2069 (1965).

5. W. Lapeyre, H. Cheradame, N. Spassky, and P. Sigwalt, J. Chim. Phys. Chem. Biol., 5, 838 (1973).

6. N. Oguni, K. Lee, and H. Tani, Macromolecules, 5, 819 (1972).

7. J. Schaefer, Macromolecules, 5, 590 (1972).

8. A. Borgne, N. Spassky, C. L. Jun, and A. Momtaz, Makromol. Chem., 189, 637 (1988).

9. M. Ishimori, T. Hagiwara, and T. Tsuruta, Makromol. Chem., 179, 2337 (1978).

10. N. Oguni, S. Shinohara, and K. Lee, Polym. J., 10,
755 (1979).

11. F. C. Schiling and A. E. Tonelli, Macromolecules, 19, 1337 (1986).

12. N. Spassky, Makromol. Chem., Macromol. Symp., 42/43, 15 (1991).

13. T. Uryu, H. Shimazu, and K. Matsuzaki, Polym. Lett., 11, 275 (1973).

14. T. Hagiwara, Y. Terasaki, H. Hamana, T. Narita, J. Umezawa, and K. Furuhashi, Makromol. Chem., Rapid Commun., 13, 363 (1992).

15. D .S. Smith, R. M. Murch, and O. R. Pierce, Ind. Eng. Chem., 49, 1241 (1957).

16. J. B. Coenat and C. O. Tongberg, J. Am. Chem. Soc., 52, 1659 (1930).

17. F. D. Trischler and J. Hollander, Polym. Prepr. Am. Chem. Soc., Div. Polym. Chem., 8, 491 (1967).

18. F. D. Trischler and J. Hollander, J. Polym. Sci., $A-1$, 5, 2343 (1967).

19. K. Furuhashi, Chirality in Industry, 167 (1992).

20. C. von dem Bussche-Hünnefeld, C. Cescato, and D. Seebach, Chem. Ber., 125, 2795 (1992).

21. M. Ishimori, T. Tomoshige, and T. Tsuruta, Makromol. Chem., 120, 161 (1968).

22. M. Ishimori, T. Hagiwara, T. Tsuruta, Y. Kai, N. Yasuoka, and N. Kasai, Bull. Chem. Soc. Jpn., 49, 1165 (1976).

23. R. E. Parker and N. S. Isaacs, Chem. Rev., 59, 758 (1959).

24. H. C. Chitwood and B. T. Freure, J. Am. Chem. Soc., 68, 680 (1946).

25. E. T. McBee, C. E. Hathaway, and C. W. Roberts, J. Am. Chem. Soc., 78, 3851 (1956).

26. O. Takahashi, K. Furuhashi, M. Fukumasa, and T.Hirai, Tetrahedron Lett., 31, 7131 (1990).

27. T. Nakajima, S. Suga, T. Sugita, and K. Ichikawa, Tetrahedron, 25, 1807 (1969). 